\title{
Spectrum Analysis of Tropical Cloudiness (II)
}

\author{
By H. Tanaka and O. Ryuguji \\ Kashima Branch, Radio Research Laboratories, Ibaraki-Ken \\ (Manuscript received 6 March 1972, in revised form 9 March 1973)
}

\begin{abstract}
The behaviors of the cloud systems in the tropical Pacific region were analyzed by making use of the spectral method especially paying attention to the lateral propagations of the disturbances. Throughout the analysis, two kinds of disturbances were found: one belongs to the longer period than ten days and another does to the short period with four or five days. The longer period cloud system is estimated to be propagated from the mid-latitude to the equatorial zone at nearly $130-140^{\circ} \mathrm{W}$. Such behavior of the long-period disturbance satisfies the theoretical regime of lateral propagation. The shorter period cloud system may be self-induced within the equatorial zone.
\end{abstract}

\section{Introduction}

The purpose of the present paper is to continue the spectrum analysis with respect to the behaviors of the tropical cloudiness in more detail than in the previous paper by the same authors (1971) (namely Paper-I). In Paper-I, we limit the region for analysis to only a latitudinal zone $6-11^{\circ} \mathrm{N}$. We are going to extend the region for analysis from the equator to $20-25^{\circ} \mathrm{N}$ zone in the present paper especially in order to examine the behaviors of the cloud systems to the meridional direction.

Where the sources of the disturbances with the various periods are there, that is, whether within the equatorial region or from the mid-latitude region? Charney (1969) concluded that the westward propagating disturbances cannot invade far into the easterly regime. Mak (1969) emphasized that the mean shear makes a significant role for the lateral coupling. Bennett and Young (1971), however, obtained a possibility for lateral propagation into the Tropics by the numerical analysis of one-layer model on an equatorial $\beta$-plane such as Matsuno (1966).

We do not always expect that all the disturbances in the equatorial region are the propagated ones from the mid-latitude. Hayashi (1970) investigated the possibility of the induced waves within the equatorial region. In the present paper, the analysis of such induced waves is also attempted statistically.

\section{Data used}

Data used in the present paper are taken from the SSCC pictures* which have been successively recorded by NASA from 1 January to 30 June in 1967. The pictures recorded during nearly 21.00 22.00 UT are selected in order to take fully round earth images. As is shown in Fig. 1, the cloud amounts are measured at every ten degree longitudinal interval from the equator to $25^{\circ} \mathrm{N}$. The cloud amounts are evaluated in $0,1, \cdots \cdots, 10$

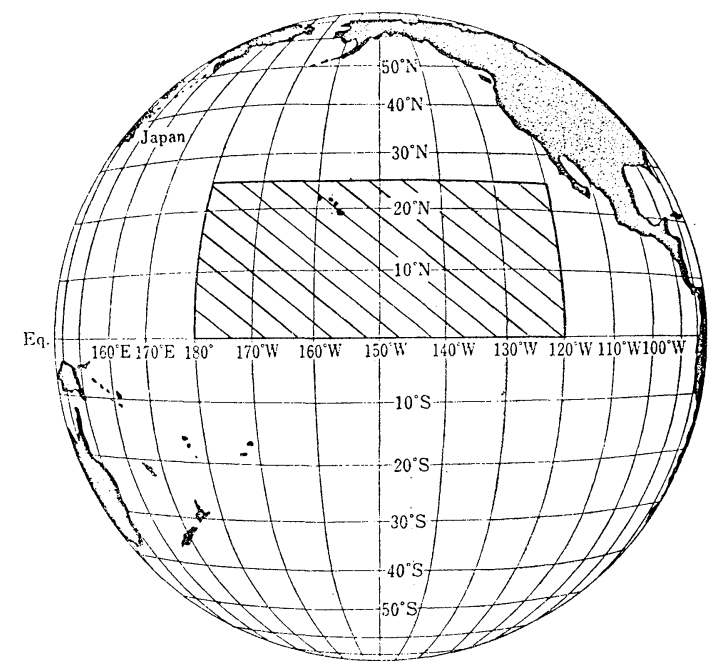

Fig. 1. Region for the present analysis

* The ATS-I Meteorological Data Catalog Vol. I 


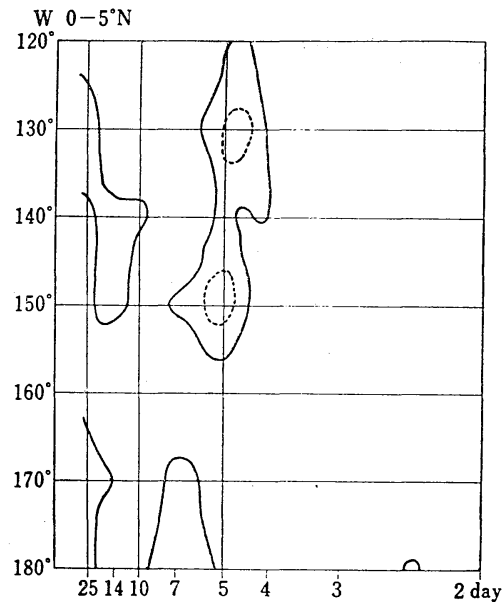

(a)

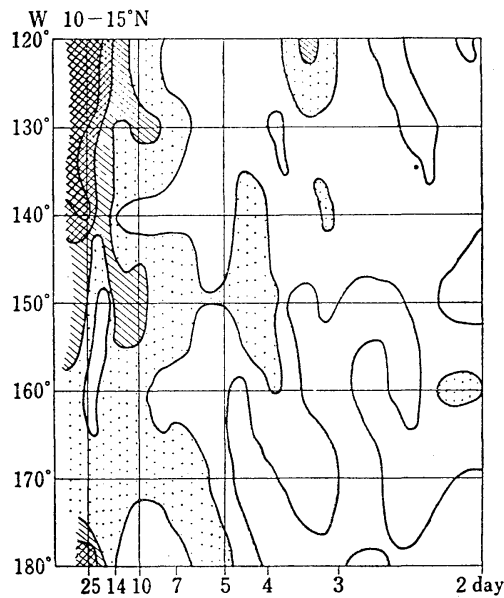

(c)

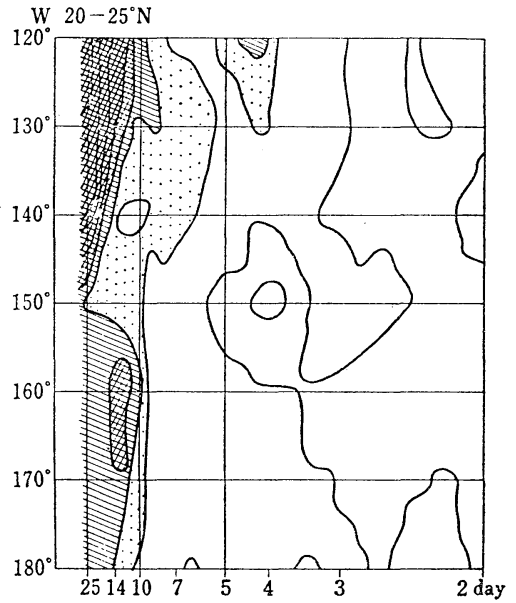

(e)

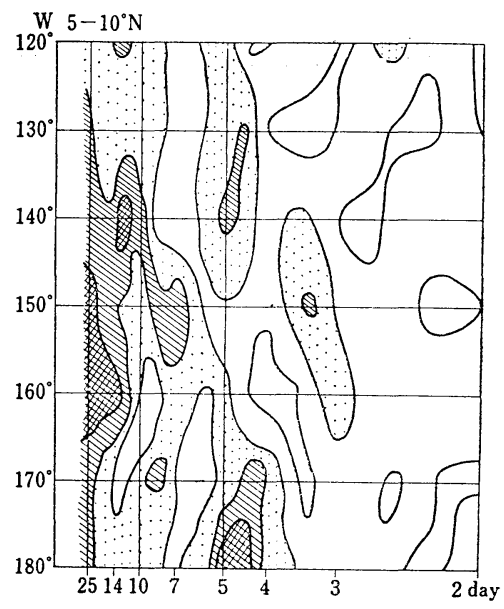

(b)

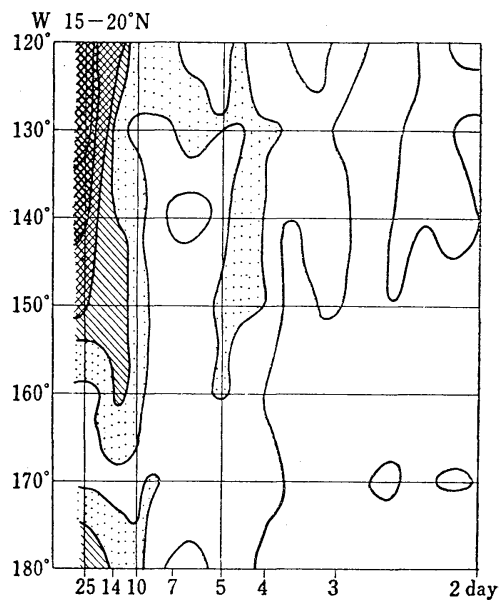

(d)

Fig. 2. Period-longitude sections of density distributions of cloudiness spectra in each latitudinal zone: (a) $0-5^{\circ} \mathrm{N}$, (b) $5-10^{\circ} \mathrm{N}$, (c) $10-15^{\circ} \mathrm{N}$, (d) $15-$ $20^{\circ} \mathrm{N}$, (e) $20-25^{\circ} \mathrm{N}$. Contours show the spectral values of $10,20,30$ and 40 in due order. 
grade at thirty five points in the shaded region in Fig. 1. Hence, we can prepare the thirty five time sequences (a picture per day) of cloudiness. In the present paper, the region considered for analysis is extended so far as the mid-latitude compared with the region analyzed in Paper-I.

\section{Period-longitude sections of cloudiness spectra}

In Paper-I, we obtained the period-longitude section of cloudiness spectra in a zone bounded by two latitudes, that is, $6^{\circ} \mathrm{N}$ and $11^{\circ} \mathrm{N}$ and found that there exist some disturbances with periods more than ten days. We obtained the period-longitude sections for five latitudinal zones $\left(0-5^{\circ} \mathrm{N}, 5-10^{\circ} \mathrm{N}, 10-15^{\circ} \mathrm{N}, 15-20^{\circ} \mathrm{N}\right.$ and 20 $25^{\circ} \mathrm{N}$ ) which are illustrated in Fig. 2(a), (b), (c), (d) and (e). The $0-5^{\circ} \mathrm{N}$ zone is most adjacent to the equator and has poor cloudiness through all year round. The typical peaks of the spectral densities of cloudiness are observed at 5-day period in the eastern region (Fig. 2(a)). The spectral densities with longer period than ten days are weaker than those with 5-day period. Hence, the disturbance with 5-day period would be most typical in this zone.

The longer periods than ten days become noticiable in $5-10^{\circ} \mathrm{N}$ zone though the 5 -day period disturbance is still recognized. This zone occupies almost common area studied in Paper-I. The disturbances with approximately semi-monthly period are recognized in the mid-longitudinal region (nearly $135-165^{\circ} \mathrm{W}$ ).

The waves with 5 -day period become insignificant in higher latitudes than $10^{\circ} \mathrm{N}$. On the other hand, the disturbances with the periods such as longer than 14 or 25 days appear in the eastern longitudinal region as are shown in Fig. 2(c), (d) and (e). The region bounded by nearly $160^{\circ} \mathrm{W}$ and $170^{\circ} \mathrm{W}$ in longitude and also by $10^{\circ} \mathrm{N}$ and $20^{\circ} \mathrm{N}$ in latitude has poor spectral values through all periods. The disturbance with approximately 25-day period appears again in nearly $180^{\circ}$ in longitude.

We can get some results, through above analysis, about the spectral behaviors of cloudiness for each latitude. In the latitudinal zones adjacent to the equator (i.e., $0-5^{\circ} \mathrm{N}$ and $5-10^{\circ} \mathrm{N}$ ), the wave with nearly 5-day period is considerably predominant. The waves with longer periods than ten days are still recognized in the mid-region of longitude. These waves become significant and are spread to longer period in higher latitudinal zones (i.e., $10-25^{\circ} \mathrm{N}$ ). On the contrary, the wave with 5-day period decays in such high latitudinal zones. Hence, the shorter period disturbance would be generated in adjacent zones to the equator.

\section{Period-latitude sections of cloudiness spectra}

In the present section, the period-latitude diagrams of the spectral densities of cloudiness are discussed for each longitude in order to examine the meridional behaviors of the spectra which are shown in Fig. 3 (a), (b), (c), (d), (e), (f) and (g). In the eastern region of the Pacific (i.e., $120-140^{\circ} \mathrm{W}$ ), the spectral values of longer period than ten days are predominant particularly in the higher part of the latitude as are shown in Fig. 3 (a), (b) and (c). The spectral peaks of the disturbances with such long periods gradually shift toward the equator. In each region of $150^{\circ} \mathrm{W}, 160^{\circ} \mathrm{W}$ and $170^{\circ} \mathrm{W}$, the spectral peaks of the long period appear in $5-10^{\circ} \mathrm{N}$ zone though there also exist such peaks in the northern latitudes (Fig. 3 (e), (f) and (g)). The disturbances with 4-5 day period are predominant at both sides of the examined region in longitude. Especially at the eastern side they have noticiable peaks. Such kinds of disturbances generally have their spectral peaks in $5-10^{\circ} \mathrm{N}$ zone of latitude except only a case at $120^{\circ} \mathrm{W}$.

\section{Spectral features of disturbances with long and short periods}

The spectral features of the disturbances considered in the previous two sections are summarized especially with respect to the long-period disturbances longer than ten days and the short-period ones nearly four or five days. Fig. 4(a) shows the spectral magnitudes of the cloudiness with respect to the 4-5 day period disturbances in the tropical Pacific region. The spectra are more predominant, though slightly, in both $170^{\circ} \mathrm{W}-180^{\circ}$ and $130-140^{\circ} \mathrm{W}$ on $5-10^{\circ} \mathrm{N}$ zonal area. This result describes that the short-period disturbances may be generated in the equatorial cloud band. There would not be any possibility of lateral propagation from the mid-latitude area. The comparatively large values which appear in $120^{\circ} \mathrm{W}$ and $20-25^{\circ} \mathrm{N}$ would not necessarily be systematic and significant.

The spectral magnitudes of the long-period disturbances are particularly remarkable in the north-east part of the region analyzed as is 


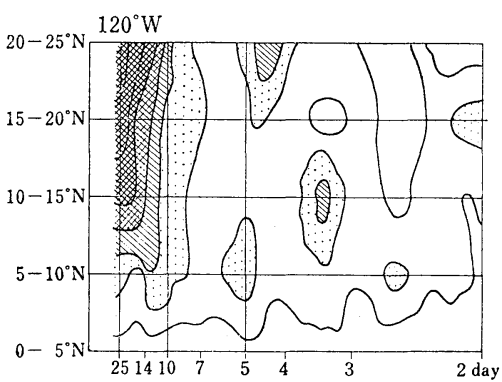

(a)

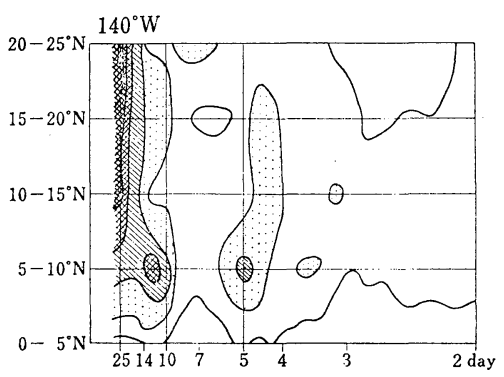

(c)

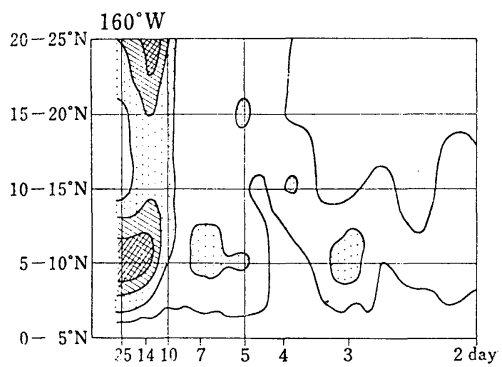

(e)

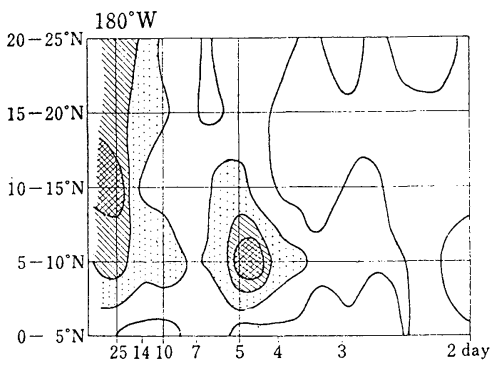

(g)

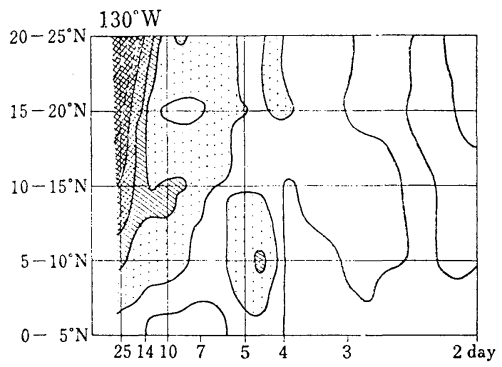

(b)

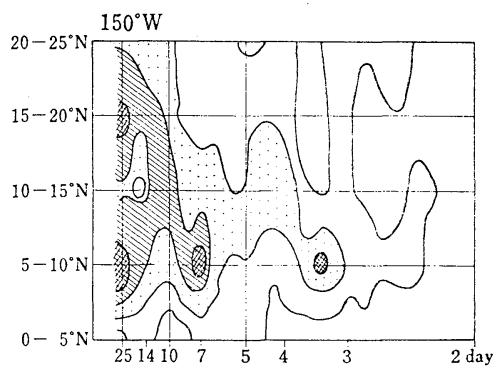

(d)

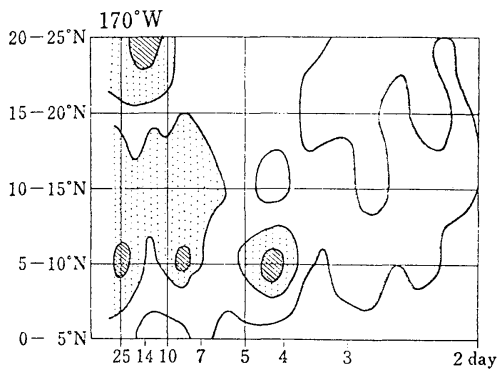

(f)

Fig. 3. Period-latitude sections of density distributions of cloudiness spectra in each longitude: (a) $120^{\circ} \mathrm{W}$, (b) $130^{\circ} \mathrm{W}$, (c) $140^{\circ} \mathrm{W}, \quad$ (d) $150^{\circ} \mathrm{W}$, (e) $160^{\circ} \mathrm{W}$, (f) $170^{\circ} \mathrm{W}$, (g) $180^{\circ}$. Contours show the same values as Fig. 2. illustrated in Fig. 4 (b). The figure seems to describe that such long-period disturbances would invade down to the equatorial zone from the north-east part.

\section{Phase propagations of disturbances}

In order to obtain the more detailed behaviors of the long-period disturbances, the phase propagations of the disturbances in each latitudinal zone are derived by filtering each time series of cloudiness. Only the disturbances with the period between nine and nineteen days are obtained by the digital band-pass filter given by 


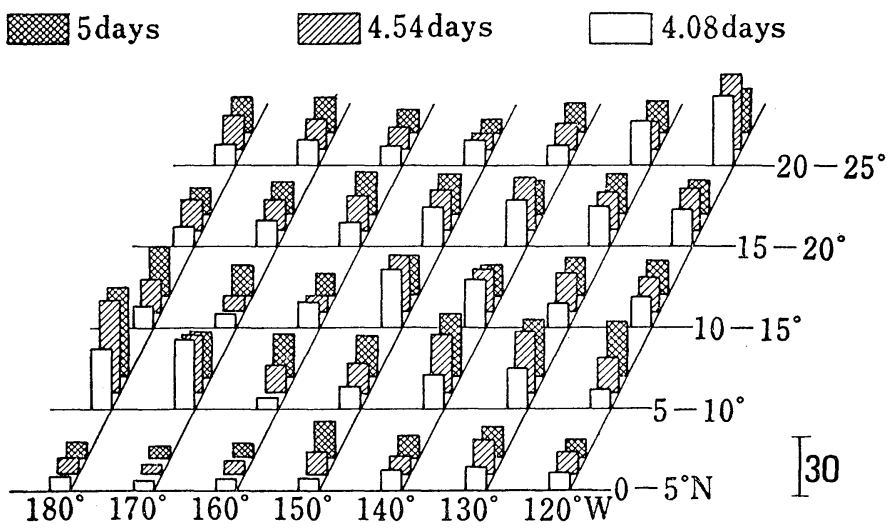

(a)

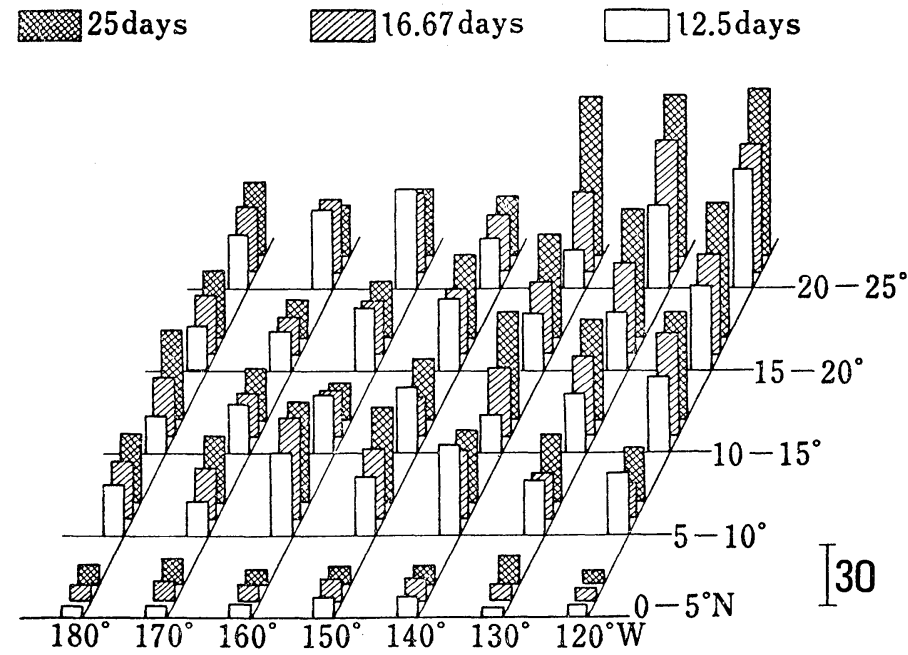

(b)

Fig. 4. Spectral magnitudes of cloudiness systems in a region for analysis:

(a) Short-period systems with 4-5 days

(b) Longer period systems than ten days.

$$
F(\omega)=\sin \left(\frac{\omega T_{2}}{2}\right) /\left(\frac{\omega T_{2}}{2}\right)-\sin \left(\frac{\omega T_{1}}{2}\right) /\left(\frac{\omega T_{1}}{2}\right)
$$

where $T_{1}$ and $T_{2}$ denote the longer and shorter periods of the band-pass-filter respectively and $\omega=2 \pi / T$ the frequency. When $T_{1}=19$ days and $T_{2}=9$ days, the response function takes the maximum value at $T=16$ days $(\omega=0.392 /$ day $)$ as shown in Fig. 5. It may be capable of deriving the phase velocity of the disturbance quantitatively from the phase difference of cloudiness between two points, but the desired accuracy is not satisfied by such method due to the coase reading interval of the data of cloudiness used. Fig. 6 (a), (b), (c) and (d) show the time sections of the cloudiness in latitudinal zones: $5-10^{\circ} \mathrm{N}, 10-15^{\circ} \mathrm{N}, 15-20^{\circ} \mathrm{N}$ and $20-25^{\circ} \mathrm{N}$ respectively. The time section of the cloudiness in $6-11^{\circ} \mathrm{N}$ zone made of SSCC pictures was partly shown in Paper-I and fairly corresponds to the present time section in $5-10^{\circ} \mathrm{N}$

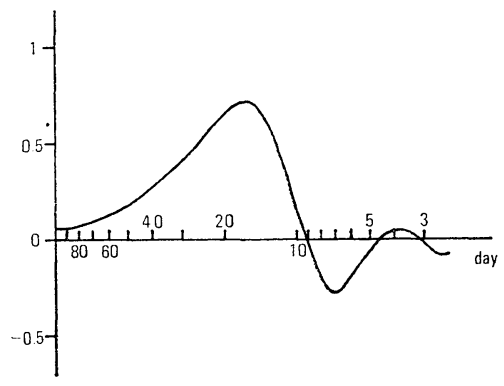

Fig. 5. Response function of the band-pass-filter used. 


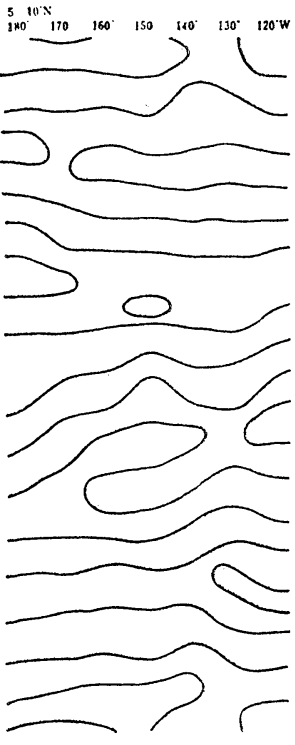

(a)

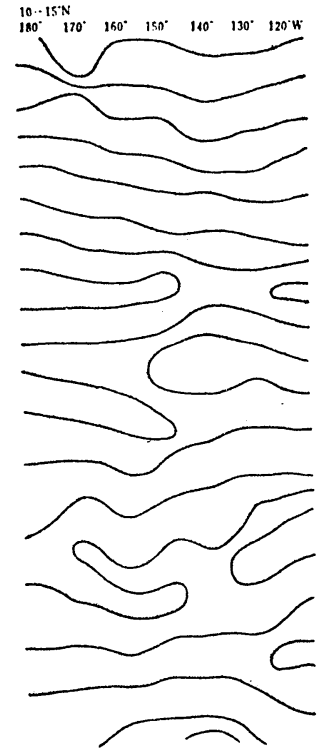

(b)

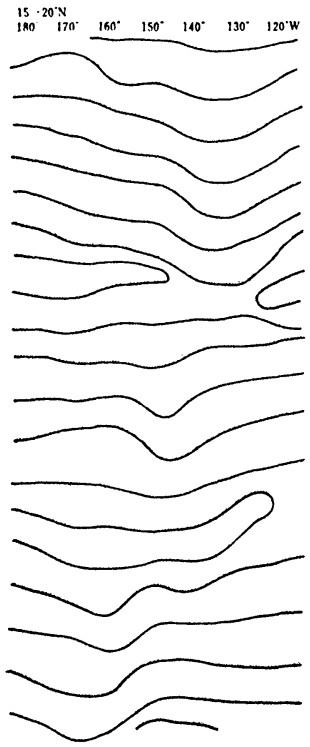

(c)

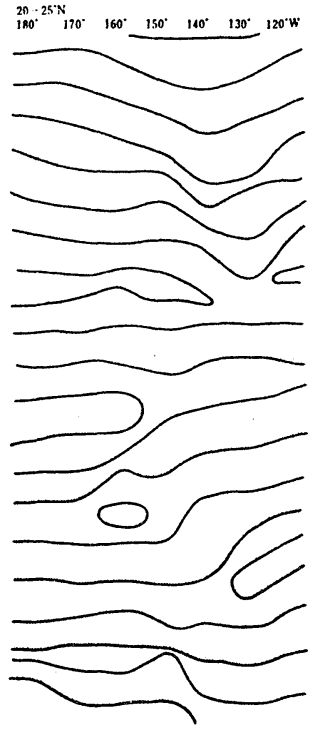

(d)

Fig. 6. Time sections of cloudiness by band-pass-filtering in each latitudinal zone: (a) $5-10^{\circ} \mathrm{N}$, (b) $10-15^{\circ} \mathrm{N}$, (c) $15-20^{\circ} \mathrm{N}$, (d) $20-25^{\circ} \mathrm{N}$. Dates of the up-side and the down-side correspond to 10 January and 20 June in 1967 respectively. The data during 10 days of both sides are removed due to running mean filtering.

zone illustrated in Fig. 6 (a). In early stage of the analyzed duration (i.e., January and February), the considering cloud systems in $20-25^{\circ} \mathrm{N}$ and $15-20^{\circ} \mathrm{N}$ propagate westwards in the eastern region of nearly $135^{\circ} \mathrm{W}$ and, on the contrary, eastwards in the opposite region. The influence of the phase propagations is gradually diluted with the lower latitudinal zones. The scale of the westward propagating cloud system on 20 $25^{\circ} \mathrm{N}$ zone is estimated approximately $4,000 \mathrm{~km}$ and gradually increases with approach to the equator. The cloud system reaches $8,000 \mathrm{~km}$ on $10-15^{\circ} \mathrm{N}$ zone (see Fig. 7 (a)). Here we define the scale of cloud system as the product of the period derived from power spectrum and the phase velocity derived by filtering method.

Although there exists a front where the collisions of the opposite phase propagations occur also in the later stage (i.e., March, April, May and June) of the cloudiness series, it is not so remarkable as a front appearing in the early stage and shifts fairly westwards. In this season, the scales of the cloud system reaches approximately 10,000 km (see Fig. 7 (b)).

\section{Lateral propagations}

Bennett and Young (1971) investigated the

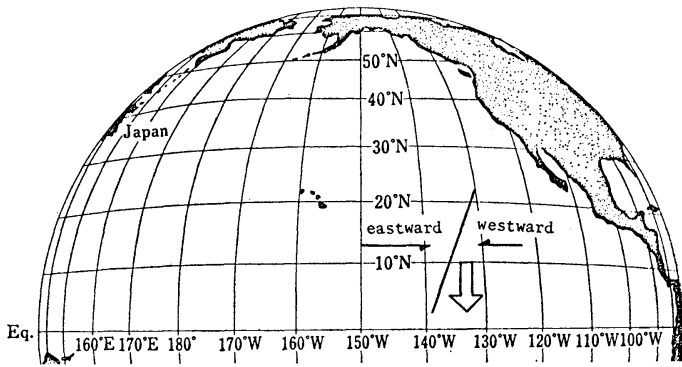

(a)

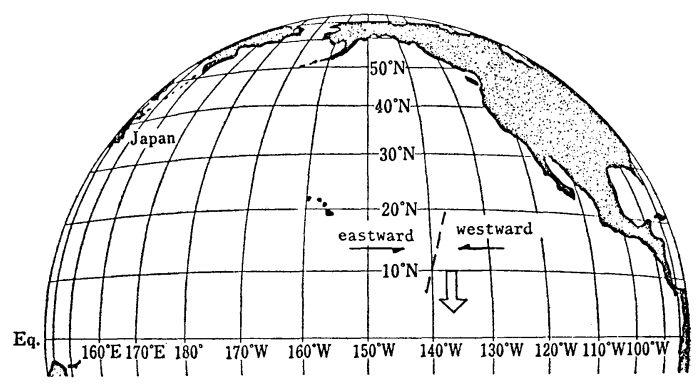

(b)

Fig. 7. Schematic figures of lateral propagations from mid-latitude to the equatorial area:

(a) In early stage of the analyzed period (i.e., Jan. and Feb.)

(b) In later stage of the analyzed period (i.e, Mar., Apr., May and June) 
lateral propagation of the disturbances in the Tropics by numerical analysis and concluded that the disturbances with phase speeds more westward than the mean flow may be free to propagate into the Tropics, providing their wavelength are not too short. The results analyzed in the previous sections may coincide with the theoretical conclusions by Bennett and Young. According to Mak (1969), a fair approximation of the horizontal mean wind throughout the troposphere is given

$$
U(y)=-0.04+0.0625 y^{2}(100 \mathrm{~m} / \mathrm{sec})
$$

where $y$ is the latitudinal co-ordinate. This gives $4 \mathrm{~m} / \mathrm{sec}$ westerly at $y=1.5\left(\approx 30^{\circ} \mathrm{N}\right)$. We find from Fig. 5 (a), (b), (c) and (d) that the westward phase speeds take approximately $4 \mathrm{~m} / \mathrm{sec}$ as their minimum value especially in the earlier stage of the analyzed period. Thus we infer that the westward phase speed derived by Mak (1969) is plausible. Furthermore, the scales of the analyzed disturbances of westward moving cloud system with long period are not too small (i.e., 4,000$10,000 \mathrm{~km})$. These facts satisfy the conditions of the lateral propagation of the disturbances into the Tropics proposed by Bennett and Young (1971).

It would be necessary to show the phenomenological features of the lateral propagation of the cloud systems.

\section{Concluding remarks}

Throughout the spectral way of analysis of the tropical Pacific region, we conclude that the following:

(i) We found two kinds of disturbances, one of which has the longer period than ten days and another of which has the short period of four or five days.

(ii) The short-period disturbances are rather predominant adjacent to the equator. Hence, such kind of disturbances would be self-induced within the Tropics.

(iii) The long-period disturbances are most remarkable in the north-east region (i.e., $120-140^{\circ}$ $\mathrm{W}$ range on $15-25^{\circ} \mathrm{N}$ zone) and gradually decrease in spectral magnitude downward the equator.

(iv) The long-period disturbances move westwards or eastwards according to the eastern or western region respectively than nearly 135$140^{\circ} \mathrm{W}$. The scale of the westward moving cloud systems covers from approximately $4,000 \mathrm{~km}$ to $10,000 \mathrm{~km}$. (v) The westward moving cloud systems satisfy the condition proposed by Bennett and Young (1971) associated with the lateral propagation of the disturbances from mid-latitude region to the equatorial region.

Hence, we may conclude that, in the westward moving cloud systems which are predominant within the eastern region than nearly $135^{\circ} \mathrm{W}$, the energy would be fed from the mid-latitude disturbances by way of the southward propagation. Although we have not any definite knowledge with respect to origin of such propagating cloud systems, the following conjecture may be reasonable. The westward propagating cloud system seems to be generated from the western edge of the cloudless area over the California Peninsula. On the contrary, the eastward moving cloud system may be identical with the cold front which is generated in the north pole area and propagates down to the equator. Both theoretical investigations and the data analyses are too poor to convincingly verify the obtained results in the present paper. In this regard, the authors found the paper by Sikdar et al (1972) after the completion of the present manuscript. The data used are common in both period and area to some extent. Further, the results obtained by them are in well agreement with the present ones particularly in regard to propagatability and periodicity of the cloud systems in the considering area.

\section{References}

Bennett, J. R. and J. A. Young, 1971: The influence of latitudinal wind shear upon large-scale wave propagation into the Tropics. Mon. Wea. Rev., 99, 202-214.

Charney, J. G., 1969: A further note on large scale motions in the Tropics. J. Atmos. Sci., 26, 182-185.

Hayashi, Y., 1970: A theory of large-scale equatorial waves generated by condensation heat and accelerating the zonal wind. J. meteor. Soc. Japan, 48, 140-160.

Mak, M.-K., 1969: Laterally driven stochastic motions in the Tropics. J. Atmos. Sci., 26, 41-64.

Matsuno, T., 1966: Quasi-geostrophic motions in the equatorial area. J. meteor. Soc. Japan, 44, 25-42.

Sikdar, D. N., J. A. Young and V. E. Suomi, 1972: Time-spectral characteristics of large-scale cloud systems in the tropical Pacific. J. Atmos. Sci., 29, 229-239.

Tanaka, H. and O. Ryuguji, 1971: Spectrum analysis of tropical cloudiness (I). J. meteor. Soc. Japan, 49, 13-19. 


\section{熱帯の雲のスペクトル解析 (II)}

\section{田中浩・竜宮寺修 \\ 電波研究所鹿島支所}

熱帯損乱の水平伝播に注目して, 熱帯太平洋における雲系の振舞がスペクトル解析を使って調べられた. 解析の結 果, 10 日以上の周期をるつ擾乱と 4,5 日周期の擾乱が見出された. 10 日以上の周期をもつ擾乱は経度 $130 \sim 140^{\circ} \mathrm{W}$ の領域で中緯度から赤道領域に伝播してくると推定される. 一方短い周期の擾乱は赤道領域内部で発生すると考只ら れる. 